\title{
Contradições do processo de disciplinamento escolar: os "Livros de Ocorrências" em análise
}

\author{
Débora Cristina Fonseca \\ Instituto de Biociências, Universidade Estadual Paulista "Julio de Mesquita Filho" (UNESP-Rio Claro) \\ Leila Maria Ferreira Salles \\ Instituto de Biociências, Universidade Estadual Paulista "Julio de Mesquita Filho" (UNESP-Rio Claro) \\ Joyce Mary Adam de Paula e Silva \\ Instituto de Biociências, Universidade Estadual Paulista "Julio de Mesquita Filho" (UNESP-Rio Claro)
}

\begin{abstract}
Resumo
Historicamente, as escolas assumiram como missão o disciplinamento de crianças e jovens, supostamente com o objetivo de adequá-los ao convívio e às normas sociais. Um dos instrumentos criados para exercer este ofício são os chamados "Livros de Ocorrências", existentes nas escolas desde a década de 1920. Neste contexto, buscamos compreender como esses livros têm sido utilizados nas escolas atualmente, como esta utilização tem sido interpretada pelos professores e quais os sentidos dos registros. Em nossa análise apontamos que os registros têm pouca efetividade em termos de favorecimento à aprendizagem do aluno, mas que exercem uma função de disciplinamento e normalização. Pôde-se também apontar, com base na análise de entrevistas com os professores, nas quais utilizamos a técnica de grupo focal, que os registros tendem a ganhar um novo significado, de proteção da escola e dos professores, ainda que esta proteção possa ser compreendida mais como simbólica do que propriamente efetiva.
\end{abstract}

Palavras-chave: Escolas, violência escolar, disciplina.

\section{Contradictions in the school discipline process:analyzing incident books"}

\begin{abstract}
:
Historically, schools have taken on the mission of disciplining children and teenagers, supposedly with the purpose of making them fit in society and adapting to social norms. One of the instruments which was used for this purpose is called "Incident Books", and have been around schools since 1920. Taking this into account, we tried to understand how these books are used in schools nowadays, how using them has been interpreted by teachers and what are the teachers' feelings about the registers. In our analysis, it can be pointed out that the registers are not very effective in terms of the pupil wanting to learn, but they play a role of disciplining and standardizing. It can also be observed that, based on the analysis of interviews with the teachers in which we used the focus group technique the registers tended to take on a new meaning, rather protecting schools and teachers, even though this protection can be understood more as symbolic than effective.
\end{abstract}

Palavras-chave: Schools, school violence, discipline.

\section{Contradicciones del proceso de disciplinamiento escolar: los "Libros de Registro de Eventos" en análisis}

\section{Resumen}

Históricamente las escuelas han asumido como misión el disciplinamiento de niños y jóvenes supuestamente con el objetivo de adaptarlos al convivio y a las normas sociales. Uno de los instrumentos creados para ejercer este oficio son los llamados "Libros de Registro de Eventos" existentes en las escuelas desde la década de 1920. En este contexto se busca comprender cómo estos libros han sido utilizados en las escuelas actualmente, cómo este uso ha sido interpretado por los profesores y cuáles los sentidos de los registros. Nuestro análisis señala que los registros tienen poco efecto para favorecer el aprendizaje del alumno, sin embargo ejercen una función de disciplinamiento y normalización. También se podría apuntar, sobre la base del análisis de entrevistas con los profesores realizadas con la técnica de grupo focal, que los registros tienden a adquirir un nuevo significado: de protección de la escuela y de los profesores, aunque esta protección pueda ser comprendida más como simbólica que propiamente efectiva.

Palabras Clave: Escuelas, violencia escolar, disciplina. 


\section{Introdução}

Desde sua origem a escola tem como missão primordial o disciplinamento de crianças e jovens, supostamente adequando-os ao convívio social. Assim, a proposta educativa tem sido, em grande medida, a socialização das pessoas, notadamente no sentido restrito de adequação às normas sociais. Para cumprir esta missão foram criados vários mecanismos de controle, disciplinamento e manutenção da autoridade.

Uma das formas mais tradicionais de controle e disciplinamento instituídas pelas escolas são os chamados "Livros de Ocorrências" ou "Livro Preto". Este mecanismo já recebeu várias denominações (Livro de Penalidades de Alunos, Termo de Censura, Livro de Sanções, entre outros), mas com o mesmo objetivo: o cumprimento das normas das escolas pelos alunos, professores e funcionários (Moro, 2002).

Moro (2002) encontrou como antecedente mais remoto deste tipo de registro o "Código de Ensino do Estado do Paraná", criado em 1917. Este documento estabelecia os deveres dos alunos e também as sanções. Estabelecia ainda que o professor deveria explicar aos alunos o artigo referente aos seus deveres e que a disciplina escolar deveria ser essencialmente preventiva e basear-se no bom exemplo. Outra nuança do referido código diz respeito aos pais, estabelecendo que estes deveriam ter conhecimento de todas as faltas cometidas por seus filhos na escola, sendo também responsabilizados.

Neste início do século XXI esta prática ainda vigora, ou seja, os Livros de Ocorrências ainda são utilizados na maioria das escolas públicas em todo o território nacional; porém sua utilização parece ter sofrido mudanças quanto aos objetivos iniciais que supostamente teriam prescrito os registros. Em alguns estados os registros constam como um procedimento previsto no regimento escolar como condição para aplicação das normas disciplinares. Desta forma, parece ser uma definição de cada unidade escolar a implementação desses registros, tendo-se instituído como prática, na maioria dessas unidades, os chamados Livros de Ocorrências.

Procurando entender melhor a função dos Livros de Ocorrências no cotidiano das escolas públicas, o presente trabalho refere-se ao estudo desses livros e do significado dos registros feitos por professores de duas escolas públicas do Interior Paulista. Os dados foram coletados buscando-se compreender o cotidiano das duas escolas. A primeira (Escola 1) era tida pela mídia e pelo imaginário social como violenta. A outra (Escola 2), ao menos aparentemente, teria menos problemas relacionados à violência, e seria, grosso modo, mais respeitada pela comunidade. As escolas 1 e 2 inseriam-se, não obstante, na mesma comunidade, socialmente identificada como foco de violência, em uma cidade do Interior do Estado de São Paulo (Brasil). Ambas eram unidades escolares pertencentes à rede púbica estadual.

Partindo do pressuposto de que todos os fatos importantes acontecidos no cotidiano escolar seriam lançados nos referidos livros, já que sua existência é prática comum nas escolas da rede pública do Estado de São Paulo, buscamos levantar os registros de alunos/fatos ocorridos entre as turmas da $6^{\mathrm{a}}$ série do Ensino Fundamental e do $1^{\circ}$ ano do Ensino Médio.

Contávamos com a informação inicial dos gestores, de que os registros eram realizados pelos próprios professores logo após o ocorrido e, em alguns casos, com intermédio da direção e ou da coordenação (o registro era realizado pelo coordenador/diretor da escola, assim como a providência anotada por estes, quando os pais são convocados a comparecer à escola). Como são poucas as informações disponíveis sobre o tema, os procedimentos de registro consistiram em um dos dados a serem levantados com os professores.

Posteriormente realizamos entrevistas utilizando a técnica de grupo focal, com os professores que mais registros haviam feito nos livros analisados no ano de 2010. Na Escola 1 participaram sete professores, e na Escola 2, cinco professores. As entrevistas em grupo focal (Gatti, 2005; Minayo, 1998) consistiram em solicitar aos professores, em grupo, que se posicionassem sobre a temática dos Livros de Ocorrências (sua finalidade, os procedimentos de registro e sua utilidade na prática cotidiana). Em cada escola foi realizada uma entrevista em grupo focal de professores, com duração aproximada de uma hora.

A análise dos dados seguiu a metodologia de análise de conteúdo, que, segundo Bardin (1988), é um instrumental metodológico através do qual se busca entender o sentido de uma comunicação.

\section{Análise dos Livros de Ocorrências}

O trabalho de coleta de dados nos Livros de Ocorrências foi precedido de entrevistas semiestruturadas (Minayo, 2008) iniciais com os gestores de cada escola, tendo-lhes sido solicitada a indicação/nomeação dos alunos considerados, pela escola como protagonistas de violência.

Após a coleta dos dados relativos a todos os alunos que tiveram registros nas séries indicadas, passou-se à identificação de todos que eram considerados protagonistas de violência, com o objetivo de verificar se esses alunos cometiam atos mais graves ou diferenciados dos demais alunos da escola.

No ano, cada sala de aula/turma tem seu Livro, no qual o professor registra as ocorrências de sua aula. $\mathrm{Na}$ leitura dos registros, há indícios de que são registradas situações que influenciam de forma negativa o andamento das aulas.

$\mathrm{Na}$ Escola 1 foram levantados os dados de 526 alunos, em 15 turmas, totalizando 209 registros, e 62 alunos foram indicados pelos gestores como protagonistas de violência, mas apenas 47 deles tinham registros nos Livros da escola. Na Escola 2 foram levantados os dados de 726 
alunos, dos quais 93 estavam registrados nos Livros de Ocorrências, e destes, 28 estavam indicados como protagonistas, sendo que dois destes últimos haviam abandonado a escola e outros dois eram alunos com necessidades educacionais especiais.

Primeiramente procuramos mapear e identificar os tipos de ocorrência que são registrados nos livros. Após este primeiro levantamento, realizamos o mesmo procedimento somente em relação aos alunos considerados protagonistas de violência.

$\mathrm{Na}$ Escola 1, os atos considerados pelos docentes como de transgressão às normas que fundamentam uma boa aprendizagem escolar - como não realizar as tarefas escolares e não participar da aula -, eram os mais frequentes nos cadernos analisados. Registros desta natureza, que eram os mais repetitivos, totalizavam 174 , o que correspondia a $20,37 \%$ das ocorrências.

Nos registros apareciam com bastante frequência fatos como: não levar material para a aula, conversar muito, andar pela sala, portar/usar celular, jogar bolinhas de papel, sair da sala de aula sem autorização e gritar em sala de aula.

Os registros dos alunos considerados pela coordenação como protagonistas de violência na escola indicavam que também entre eles os incidentes mais comumente registrados eram: não realizar as atividades em sala de aula e /ou não participar da aula, sendo que um mesmo aluno chegou a somar sete registros neste comportamento, anotados por diferentes professores: agir de forma indisciplinada, conversando constantemente durante as aulas e principalmente durante as explicações; atrapalhar a aula; desrespeitar o professor.

Assim, ao observarmos as situações registradas, pudemos verificar que os alunos em geral e os protagonistas de violência apresentavam características similares. Os principais itens registrados para os alunos em geral repetiam-se quando eram observados os dados dos alunos considerados protagonistas de violência.

Os registros dos alunos indicados pelos gestores como protagonistas de violência apontavam que eles constantemente se envolviam em situações consideradas de desrespeito e de desacato ao professor, e que atrapalhavam a aula. Embora os demais alunos também tivessem registros nesse sentido, as ocorrências deste tipo pareciam ser mais frequentes entre estes últimos. Quase metade das ocorrências deste tipo registradas no Livro estavam relacionadas com os protagonistas de violência. Lembramos aqui que, segundo a literatura sobre violência na escola, os desrespeitos, os desacatos, as pequenas agressões, as grosserias e as incivilidades que se repetem sem parar são o núcleo da violência que acontece cotidianamente nas escolas, criando um clima de insegurança no ambiente escolar (Debarbieux, 2001, 2002, 2005; Charlot, 2002).

$\mathrm{Na}$ Escola 2, os principais motivos foram: brincadeiras/atrapalhar a aula; não realizar atividades em sala de aula e /ou não participar da aula; passear fora da sala de aula (durante horário de aula); indisciplina (conversar muito). Assim, os registros mais comuns na Escola 2 se referiam a brincadeiras que atrapalhavam a aula e a não realizar atividades ou não participar das aulas, como o que apresenta a Escola 1, embora com um índice percentual bem menor.

Registros referentes a alunos que permaneceriam fora da sala em horário de aula eram os mais comuns na Escola 2. Chama a atenção nos registros desta escola que a atitude tomada pelos professores/escola em relação a esse comportamento era a de manter os alunos fora da aula. Pareceu-nos a perpetuação da prática, ou seja, o aluno recebia, como punição "educativa", ser obrigado a permanecer fora da sala de aula.

O uso de palavras consideradas de "baixo calão", interpretadas como agressão verbal por alguns professores, são mais recorrentes na Escola 1. Na Escola 2 este comportamento parecia mais evidente em duas turmas de $7^{\text {a }}$ série do Ensino Fundamental. Destaque-se que, entre os alunos considerados protagonistas de violência, este dado não se apresentava relevante. Assim como na Escola 1, eram bastante comuns registros de não levar material para a aula, sair da sala de aula sem autorização, desrespeitar o professor, atrapalhar a aula e outros.

Os atos de violência, no sentido atribuído por Charlot (2001), que reserva o uso do termo para descrever situações como o uso da força ou ameaça de usá-la, provocar lesões, cometer extorsão, praticar tráfico de droga na escola ou perpetrar insultos graves a outrem sem estarem registradas nos livros de ocorrências, representavam $7,2 \%$ do total de registros da Escola 1. Do total de 52 casos, 13 foram provocados pelos alunos considerados protagonistas de violência. Estas ocorrências dizem respeito a agressões físicas e verbais dirigidas tanto a alunos quanto a professores e funcionários. Em geral, as brigas e discussões foram motivadas pelo uso de apelidos ou por conflitos mal resolvidos, como, por exemplo, "fofocas sem fundamento".

Nas duas escolas, as ocorrências mais registradas referiam-se a acontecimentos comumente presentes no cotidiano escolar: alunos não fazerem as atividades, serem indisciplinados, atrapalharem a aula. Outro registro comum se referia a chegar atrasado à aula ou mesmo deixar de entrar para a sala de aula, sendo que a principal providência tomada pela escola consistia em deixar o aluno fora da sala e registrar os fatos no Livro de Ocorrência. Esta constatação é valida para os dois grupos de alunos: os protagonistas de violência e os não protagonistas. Neste sentido, não podemos deixar de registrar que se um aluno não tem interesse em assistir a determinada aula, seu objetivo é atingido facilmente, constituindo-se em uma lógica bastante perversa, que, em nome da disciplina, pouco interfere no processo educativo que a situação evidencia como necessário.

Numa análise comparativa entre os alunos dos dois grupos - os alunos em geral e os protagonistas de violência das duas escolas - observa-se, como começamos a indicar, que em muitos aspectos eles se assemelhavam. Eles se assemelhavam em não cumprir as regras para uma boa aprendizagem escolar, no desrespeito aos professores, no uso de palavrões, e mesmo em protagonizar agressões físicas. Isto nos permite refletir sobre: 1) o significado e sentido que é 
atribuído ao desrespeito no âmbito escolar, e como a ideia de respeito é socialmente construída; 2) como a relação professor-aluno foi construída e quais eram os princípios de respeito ao outro que a permeava; 3 ) por que alguns alunos eram considerados protagonistas de violência e outros não. Cabe questionarmos ainda se as relações de respeito e autoridade eram construídas ou impostas, e mesmo se os alunos já tinham ou não estas regras internalizadas.

Entendendo significado e sentido na perspectiva vigotskiana, podemos considerar os sentidos como uma formação dinâmica, fluida e complexa, com várias zonas de estabilidade. Quanto à relação entre sentido e significado Vigotski afirma que "O significado é apenas uma dessas zonas de sentido que a palavra adquire no contexto de algum discurso e, ademais, uma zona mais estável, uniforme e exata". (2001a, p. 465).

Partindo deste pressuposto, podemos refletir sobre o significado da palavra respeito, partilhado socialmente entre professores e alunos, e as diferentes possibilidades de sentidos construídas na relação do professor com os alunos e destes entre si. Se considerarmos que, historicamente, o significado de respeito ao professor foi sendo significado pela cultura como uma relação hierárquica, baseada no medo da autoridade, e que hoje, principalmente pelo acesso à informação e pelo conhecimento dos seus direitos previstos na legislação, os alunos não mais se sentem, necessariamente, subordinados à autoridade, coloca-se o desafio de construir sentidos para a palavra respeito em uma perspectiva mais horizontal. Questionamos se existe no cotidiano escolar, além dos registros nos livros de ocorrências, ações e espaços de sociabilidade que permitam a construção de outros sentidos para a palavra respeito, considerando-se que o significado hierárquico nos parece não mais ser dotado de um sentido autêntico nas relações escolares e familiares e em grande parte das demais práticas sociais.

Do mesmo modo, as incivilidades, as pequenas agressões, o desrespeito, o uso de palavras consideradas de baixo calão, são acontecimentos recorrentes nos registros tanto dos alunos em geral como daqueles que protagonizam situações de violência, e são dirigidoss tanto aos colegas como aos educadores. Sobre este tema Barrere e Martuccelli (2001, p. 269) afirmam que nas escolas o desrespeito está associado ao fato de que os alunos "exigem respeitos horizontais", reivindicando um tratamento de igualdade entre eles e os professores.

Neste caso específico, não podemos afirmar ser esta a lógica que pauta tal comportamento, já que este estudo se limitou a analisar as ocorrências registradas nos livros da escola; mas podemos supor que, provavelmente, é esta a lógica que permite aos alunos dirigir-se aos professores com palavrões, pois utilizam essa linguagem, comumente empregada na relação entre pares, isto é, nas relações igualitárias. Construir uma relação de autoridade e respeito constitui-se em um desafio fundamental no contexto escolar, ancorado em significados diferentes daqueles que anteriormente estavam presentes nas relações escolares e subsidiavam o uso dos "Livros de Ocorrências", "Livros Pretos", como forma de disciplinamento. No contexto atual, esses instrumentos parecem ter perdido sua eficácia, já que a ideia de respeito à autoridade não mais se sustenta pelo padrão moral ou pelo medo de punição.

Situações que envolvem agressões físicas, geralmente representadas por socos, tapas ou unhadas em colega, eram registradas tanto em relação aos alunos em geral como em relação aos protagonistas de violência. Por exemplo, na Escola 1, do total de catorze registros, oito eram dos alunos classificados como protagonistas de violência. Assinala-se aqui que apenas uma ocorrência foi considerada pela escola como grave. Embora nos relatos dos gestores exista a indicação de alunos envolvidos com o tráfico de drogas, nos registros em análise nenhuma ocorrência deste tipo foi observada.

De forma geral, quando as referências eram os dois grupos de alunos, os fatos registrados nos "Livros de Ocorrências" das escolas diziam respeito à suposta inadequação dos alunos às regras da escola e às normas de uma boa convivência social escolar. Estes dados se assemelham aos de Sousa, Nascimento e Azevedo (2006), que evidenciou que a não participação na aula é um dos principais motivos para o registro em livros de ocorrências em escolas.

Desta maneira podemos supor que os atos de violência na escola, no sentido jurídico do termo, são fatos que continuam muito raros no ambiente escolar; mas as pequenas agressões, o desrespeito continuo e as incivilidades constantes (Debarbieux, 2002) geram um clima de insegurança e medo e, consequentemente, a suposição de que tudo e qualquer coisa possa ocorrer no ambiente escolar. Este clima de insegurança é corroborado pela mídia, que de forma constante apresenta, de maneira dramática, atos de violência ocorridos em escolas periféricas, atrelando violência e pobreza. Sobre isto afirma Coimbra:

Cotidianamente, os meios de comunicação nos fazem crer que se a grande massa excluída de nossa população age diferentemente das elites é porque vive e, portanto, pensa, percebe e sente diferentemente de nós. Daí, não podem receber o mesmo tratamento (Coimbra, 2001, p.17)

Comparando estes dados com os apontados na pesquisa realizada por Moro (2002), referente ao período de 1973 a 1982, é possível observar que os "problemas" atualmente vivenciados pelas escolas não são muito diferentes daqueles. Na pesquisa de Moro (2002), as faltas leves encontradas nos registros dos Livros de Ocorrências eram: indisciplina, brincadeiras nas aulas, chegada atrasada à escola, falta do uniforme, fala nos corredores e outras; e como faltas graves o desacato aos professores, desrespeito ou agressão aos colegas, o não cumprimento das obrigações escolares, pular o muro da escola, entre outras.

Estes dados nos permitem pensar que a maioria dos registros não diz respeito à violência stricto sensu, de modo que podem ser mais bem qualificadas como transgressões e incivilidades. Segundo Charlot (2002), 
...a transgressão é o comportamento contrário ao regulamento interno do estabelecimento (mas não ilegal do ponto de vista da lei): absenteísmo, não realização de trabalhos escolares, falta de respeito, etc. Enfim, a transgressão e incivilidade não contradizem nem a lei, nem o regimento interno do estabelecimento, mas as regras da boa convivência: desordens, empurrões, grosserias, palavras ofensivas, geralmente ataque quotidiano - e com frequência repetido - ao direito de cada um (professor, funcionários, aluno) ver respeitada sua pessoa (Charlot, 2002, p. 437)

Aquino (2011) nos alerta para a necessidade de meIhor compreender estes termos, principalmente quando são tomados em uma sequência pragmática. Em suas palavras:

Uma precaução no que tange à tipologia das ocorrências implica, de imediato, a diferenciação entre as noções de incivilidade, de indisciplina e de violência. Isso porque não é infrequente que os três vocábulos se apresentem amalgamados sob o mesmo manto semântico-pragmático de problemas disciplinares. Mais do que por uma ambiguidade linguística ou um vício formal, os três termos parecem ser frequentemente compreendidos como se portassem uma semelhante raiz causal, ou como se se tratasse de uma sucessão progressiva: da indisciplina à incivilidade, e desta à violência. Não há razão para sê-lo, a nosso ver (Aquino, 2011, p. 467).

Por outro lado, é preciso considerar que a compreensão sobre o que é ou não violento depende dos sujeitos que os identificam e que lhes atribuem sentidos e significados (Vigotski, 2006). Leontiev (1978) considera que os sentidos fazem parte do conteúdo da consciência e parecem entrar na significação objetiva, mas alerta que é o sentido que se exprime nas significações, e não a significação nos sentidos, portanto é necessário distingui-los:

Quando se distingue sentido pessoal e significação propriamente dito, é indispensável sublinhar que esta definição não concerne a totalidade do conteúdo refletido, mas unicamente com aquilo para que está orientada a atividade do sujeito. Com efeito, o sentido pessoal traduz precisamente a relação do sujeito com os fenômenos objetivos conscientizados (Leontiev, 1978, p.105).

Desta forma, compreender os sentidos produzidos pelos professores sobre violência e, mais especificamente sobre os registros que efetuam, coloca-nos o desafio de compreender a constituição histórica dos sujeitos e o desenvolvimento de sua consciência. Consideramos não ser possível esta profundidade de análise, mas compreender os sentidos por meio dos significados que são partilhados nos discursos dos sujeitos entrevistados e norteiam sua prática no contexto escolar cotidiano nos permite compreender o significado dos registros nos referidos livros das escolas em análise. Zaluar (2004) considera violência um termo polissêmico, e o define como: ...uma força que se torna violência quando ultrapassa um limite ou perturba acordos tácitos e regras que ordenam relações, adquirindo assim carga negativa ou maléfica. Portanto, é a percepção do limite e da perturbação (e do sofrimento causado) que vai caracterizar um ato como violento, percepção que varia cultural e historicamente (2004, p. 229).

Parece ser nesta lógica que os professores se amparam ao registrar os fatos nos Livros. Ainda que seja nesta lógica, como os alunos foram inseridos nestas regras que eles descumprem? Estarão eles, de fato, quebrando essas regras? Teriam a percepção do limite do desrespeito às regras e normas sociais partilhadas pelos professores e pela instituição escola?

Deste modo, as análises sobre os Livros de Ocorrências das escolas reforçam o que tem sido constatado nos estudos, isto é, que os atos de incivilidade, as pequenas transgressões que se reproduzem constantemente, as relações desrespeitosas que acontecem sem parar entre alunos e entre estes e os educadores, acabam por provocar um clima de insegurança que marca o cotidiano escolar.

Os atos de violência stricto sensu registrados na Escola 1 representavam $7,2 \%$ do total de registros, sendo consideradas as agressões físicas e verbais a alunos, professores e funcionários que se referiam a brigas e discussões que ocorreriam no ambiente escolar motivadas pela utilização de apelidos ou por causas que surgiram depois de conversas não muito claras ou de conteúdo dúbio. Assim, estes fatos parecem ser os que menos ocorrem. Na Escola 2 as agressões físicas, em todos os registros, representam $4,2 \%$, e as agressões verbais, $3,7 \%$.

No geral, estes atos de violência representavam uma pequena parcela dos problemas que ocorreram nas escolas e foram registrados nos livros.

Procurando compreender a lógica de registro dos fatos nos Livros, passamos à análise dos significados atribuídos por professores a estes registros.

\section{Significados dos registros para os professores}

As entrevistas foram realizadas, em grupo focal, com os professores que mais registraram nos Livros de Ocorrências no ano de 2010, nas duas escolas.

Quando questionados sobre os registros nos Livros de Ocorrências e seu significado, inicialmente alguns afirmaram que registravam problemas ocorridos em sala de aula que extrapolam, ficando insuportáveis, como afirmam os professores da Escola 2: "A gente tem algum problema na sala de aula , muitas vezes se torna insuportável, várias vezes de falar com o aluno, a gente comunica a direção" (P2); "Geralmente é quando eu não... eu percebo que o problema já agravou, ai sai da sala” (P3) 
Outros afirmaram que registravam as ocorrências por solicitação da escola, como ilustra o trecho: "É porque é pedido para nós que registre, para pedir ajuda por qualquer motivo" (E2,P1).

$\mathrm{Na}$ Escola 1 o registro é apontado como um instrumento a ser utilizado em situações mais graves, como ilustra o trecho a seguir.

Quando passa do limite do contornável e eles vão para uma agressão física ou eles vão para uma agressão verbal com o professor, a gente utiliza, ou pelo menos deveria ser essa a intenção. O caderno de anotações, o caderno de advertências, para esses casos mais sérios (E1, Prof.A).

Alguns professores relatam problemas de saúde, ou ainda, o uso de medicamentos para aliviar/suportar o cotidiano estressante, consequência do confronto estabelecido entre professores e alunos e, segundo eles, do descaso da família, como ilustram os trechos a seguir:

"...foi até o ponto em que ele conseguiu atingir uma coisa que eu não admito, certo? Foi quando ele falou assim: "Você pensa que é grande coisa, mas você não é nada, aqui você não é nada (....)"; e eu na quinta-feira já estava mal de saúde por causa da traqueíte. Eu vou cumprir com a minha palavra e vou até a PM (....); aí, quando eu chego, o escrivão falou assim: "senhora sabe que isto não vai dar em nada? (...) a esta altura os nervos já tinham pulado fora (...) todo esse questionamento muitas vezes é que leva a gente ao stress" (E1, Prof.A)

"Ai você chega em casa e toma um Rivotril e fica bem! (Prof.F)

Os professores participantes da pesquisa desenvolvida por Silva e Ristum (2010) corroboram este dado e afirmam que algumas das consequências para a atuação de um professor que é vitima de violência por parte dos alunos "dizem respeito à saúde física e mental, consequências como depressão e doenças da mente e do corpo" (p. 244); segundo as autoras, "isso seria indicativo de que consideram a violência no ambiente de trabalho capaz de gerar consequências ligadas à qualidade de vida que transcendem o exercício da prática docente" (Silva \& Ristum, 2010, p. 245).

Outro ponto destacado nas falas dos professores se referia às famílias, que também não apoiavam, pouco se importando com os registros feitos sobre seus filhos. Quando chamados, muitos pais não iam à escola, e quando compareciam, dificilmente essa presença poderia ser considerada positiva. Os pais acabavam por se aliar e defender os filhos, criticando os professores, como ilustra a fala de um professor: "A postura do pai é igual à do aluno, e às vezes a do pai é pior. Então, ele está reproduzindo o que ele vê em casa. Aí fica complicado" (Prof. E). Sobre isto, Ratto (2007) afirma:

(...) não raro, os pais são chamados pela escola na medida em que seus filhos estão acarretando problemas para o funcionamento escolar, sendo conscientizados ou cobrados a partir de discursos "prontos e fortes", que os colocam, tal qual seus filhos, também em uma posição constrangedora, com restritas margens de negociação, contestação, relativização ou exposição de suas dificuldades. Mais uma vez a verdade tende a funcionar a favor da escola (p. 206).

Não estamos afirmando ser este o caso das escolas em análise, mas que este aspecto deve ser considerado, em vez que, historicamente, as relações entre a escola e a comunidade se constituíram de forma hierárquica, sendo a primeira, não raramente, colocada na posição da detentora da verdade, enquanto os pais são muitas vezes considerados os responsáveis pela educação moral dos filhos, e como apontamos anteriormente, este código moral, de respeito hierárquico e punitivo, parece não mais ter um significado socialmente partilhado.

Assim, os professores reclamam da ausência dos pais para o diálogo, mas não indicam os espaços efetivos para esta prática. O processo de democratização e participação da sociedade brasileira, e mais especificamente, de participação dos pais na vida da escola, ainda é uma história a ser escrita. Os espaços de participação e diálogo ainda não existem efetivamente, com algumas poucas experiências exitosas.

Quanto ao que registrar, na Escola 1, os professores afirmaram registrar: agressão verbal a professores, acusação indevida ao professor, vandalismo, perjúrio, bate-boca com professor, supostamente para se protegerem; enquanto outros afirmavam que não viam diferenças entre o registro e não registro. Na Escola 2 se registrava para supostamente se ter controle da sala, sobretudo quando havia reincidências de comportamentos, ou ainda, para justificar para os pais quando o aluno dormia, quando tinha muitas faltas, e ainda para uma suposta "proteção" do professor e da escola:

“A gente faz para se proteger, para ter registro ali." (E1,Prof.D)

"Tomou-se esta resolução para se proteger do ato, porque o professor não tem mais confiança, perdeu-se o valor, não se confia em professor, não se confia em escola, e a escola faz tudo errado para o filho. $E$ eu penso que os registros é no sentido de se proteger mesmo. Eu vejo como para proteger a escola, a coordenadora, o professor e vejo a todos preocupados com essas desgraças (...) no sentido de ter um respaldo" (E2, Prof.1).

Observa-se que os professores colocaram como motivo para se registrar o de se "proteger". Afirmam que anotam as situações ocorridas em sala de aula, aquilo que os alunos fizeram, com o intuito de que, se alguém questionar alguma atitude tomada, os motivos que levaram a isto estão anotados. Parece evidente a crise de autoridade do professor, uma vez que o significado socialmente partilhado anteriormente não mais se evidencia nas relações cotidianas da escola. Assim, é possível entender que, em sua maioria, os registros se configuravam como uma forma de o professor 
proteger-se a si mesmo e a escola, construindo um "dossiê" do aluno protagonista ou não de violência.

Ratto (2007) corrobora esta análise ao afirmar que "tendo em vista que, articulados ao contexto do disciplinamento efetuado, os livros de ocorrências existem para estabelecer a verdade e proteger a escola de possíveis acusações" (p. 206).

$\mathrm{Na}$ perspectiva da autora, os livros precisam funcionar no sentido de não deixar dúvidas e estabelecer um consenso, mas considera este último problemático, uma vez que o registro é escrito "em meio a um poder que beneficia, sobretudo, as verdades que as autoridades escolares querem ou precisam estabelecer" (Ratto, 2007, p. 206)

Pelos registros, as trajetórias dos alunos de desacato, de agressões, de atrapalhar a aula, de ofender e insultar, são construídas, e assim, se eventualmente a escola tiver que adotar uma medida mais extremada, é possível justificá-la pela trajetória do aluno, que mostra que atos como esses eram recorrentes. Um docente afirmou ainda que haviam sido instruídos a agir deste modo por um promotor de justiça.

Tais afirmações podem explicar por que os livros contêm registros sobre vários alunos, e não apenas dos considerados violentos, já que registrar o comportamento dos alunos pode ser uma atitude preventiva/protetiva da instituição e dos professores.

As falas dos docentes de que os registros tinham como objetivo principal a autoproteção (defender-se) evidenciou que os registros podem ter um sentido que até então não havíamos suposto. A hipótese que tínhamos era que o registro em Livros de Ocorrências, como indicado na literatura, tinha apenas o objetivo de contribuir para o cumprimento das normas escolares pelos alunos, disciplinando-os; no entanto, o registro nos Livros de Ocorrências é uma prática cotidiana da escola, e o sentido de usar estes livros para disciplinar permanece, mesmo entre os professores entrevistados. Também, segundo os professores, não há apoio da direção quanto aos registros, contraditoriamente à fala de alguns, que afirmam ter sido orientados a efetuar o registro. Aquilo que era colocado no papel (registrado) não tinha consequências. Como apontamos antes, para os professores, registrar se tornou a própria medida, a própria providência adotada.

Embora dificilmente a suspensão se concretizasse, os alunos, segundo os docentes, começaram a "gostar do fato de que quando acumulavam três registros levavam suspensão" e ficavam no mínimo um dia em casa, dependendo da gravidade das ações em que estavam envolvidos. Os alunos chegavam até mesmo a "comemorar as suspensões". Pelos diferentes motivos apontados, os registros, de acordo com os professores, deixam de ser úteis, tornando-se apenas mais um trabalho realizado pelo professor e que não têm resultados. Sendo assim, mais um elemento de desgaste na relação professor-aluno e na construção da identidade do professor ou de sua figura de autoridade a ser respeitada; desgaste que parece gerar sofrimento psíquico no trabalho, e, em alguns casos, estresse, se não adoecimento. Este quadro agrava-se constantemente nas rotinas das escolas públicas, com várias ausências e afastamentos de professores por problemas de saúde, principalmente de ordem emocional, seguidos de acometimentos físicos.

Assim, para os professores e alunos, os livros parecem ter perdido o significado socialmente construído e partilhado por muitos anos no ambiente escolar, passando agora a se constituir em uma "prova" dos atos praticados pelos alunos, construindo-se um novo significado para os registros: a constituição de um "dossiê" dos alunos que poderá ser utilizado como defesa da escola em suas práticas cotidianas, como, por exemplo, para expulsar/transferir compulsoriamente alunos ou encaminhá-los a outras instituições, como o Conselho Tutelar, aDelegacia ou Poder Judiciário. No âmbito mais pessoal, os professores utilizam-se dos registros como forma de uma suposta autoproteção e autoafirmação diante da crise de autoridade vivenciada por esta categoria profissional nas últimas décadas, o que, na prática, contraditoriamente, evidencia sua pouca autoridade em sala de aula. Sua eficácia simbólica nos pareceu um tanto fragilizada.

Os docentes começam a buscar outras formas de controle para os acontecimentos ocorridos na sala de aula que consideram graves. Os professores, nos casos que consideram extremos, recorrem à Ronda Escola e buscam registrar boletins de ocorrência, os $\mathrm{BOs}$ (instrumento utilizado pela Polícia para registro de uma infração ou delito a ser apurado) contra os alunos.

$\mathrm{Na}$ Escola 1, três dos professores entrevistados já haviam feito boletim de ocorrência, todos motivados pelo desrespeito à figura do professor: uma aluna havia chamado a professora de "biscate" (no dicionário da língua portuguesa significa uma gíria para prostituta, meretriz), outro aluno disse que a professora não mandava na sala de aula e outro fez ameaças a um professor. A procura de advogados para saber quais são os direitos de uma pessoa perante a lei também foi levantada como uma hipótese pelos docentes; entretanto, nos Livros de Ocorrências da Escola 1 não constavam estes registros, ou seja, os fatos graves acabavam sendo registrados para providências fora da instituição escolar, o que, de certa forma, criminaliza os alunos que praticam atos de diferentes naturezas, podendo alguns ser classificados como indisciplina, incivilidade e outros como violência stricto sensu.

$\mathrm{Na}$ Escola 2 nenhum professor mencionou ter registrado boletim de ocorrência, apesar de esse registro constar nos Livros de Ocorrências da escola.

De forma geral, na análise das entrevistas com os professores que mais registros fizeram nos referidos livros, destaca-se um sentido disciplinar, mas principalmente um sentido de autoproteção, "para se defender", ao possibilitar a construção de uma trajetória comportamental dos alunos que justifique medidas mais extremadas e externas à escola. Ao mesmo tempo, indicam uma fragilização da autoridade do professor, que se sente refém dos alunos, dos quais precisam se defender constantemente. Nas falas dos professores não evidenciamos qualquer referência a aspectos pedagógicos ou educativos atrelados aos registros nos livros de ocorrências. 


\section{Considerações finais}

Este breve panorama nos leva a refletir sobre como as instituições, mais especificamente a escola, têm abordado os fatos que ocorrem no contexto escolar.

Uma primeira consideração a destacar refere-se ao fato de que, se na origem dos registros de ocorrências na instituição escola se tinha como foco a disciplina, atualmente sua função parece ser mais a de uma suposta proteção da instituição, dos professores e, ainda, contraditoriamente, uma maneira, simbolicamente frágil, de afirmação da autoridade do professor. Se antes os jovens eram considerados "delinquentes" no sentido de não respeitarem a lei, atualmente parecem ser algozes no sistema educativo, podendo ser "criminosos" antes mesmo do ato praticado. Os dados aqui apontados não indicam esta violência stricto sensu dos jovens, pressuposta pelos professores, da qual precisam se defender, e sim, comportamentos de indisciplina e incivilidades que na repetição cotidiana vão construindo um cenário representado como de violência. Além disso, quando registrados, vão se constituindo em um conjunto de provas a serem utilizadas contra os alunos e/ou familiares em defesa da escola e dos professores, uma estratégia meramente defensiva.

Como adverte Coimbra, "além da forma como são produzidos os "bandidos", os "marginais", os "criminosos" de todos os tipos, eles são ainda construídos para se responsabilizam por sua miséria, marginalidade e criminalidade". (2001, p.18)

Como pudemos observar nos registros dos livros e nas falas dos professores, as atitudes tomadas não causam nenhum efeito, são apenas mecanismos burocráticos da alegada "proteção", sem qualquer indicação de que esta prática possa ter algum efeito pedagógico e/ou educativo. Sendo assim, os educadores mostram-se bastante descrentes do processo educativo, não se mobilizando - conforme constatamos nas entrevistas - para outras práticas que não os registros em si, e quando consideram um comportamento e ou atitude como muito grave, em alguns casos, buscam a solução em autoridades externas à instituição escolar. Supomos que grande parte desse processo seja consequência da ausência de um trabalho educativo que enfrente essas questões de forma mais efetiva, que construa sentidos de autoridade e respeito no contexto escolar, em uma perspectiva horizontalizada.

Neste sentido, Corti, Freitas e Sposito (2001) afirmam que a escola brasileira, principalmente a pública, precisa encontrar práticas educativas que sejam capazes de proporcionar uma formação cultural e científica mais democrática e menos excludente.

Sobre os Livros de Ocorrências e sobre os comportamentos dos jovens e de suas famílias, em uma observação geral, os registros parecem ser mobilizados por entendimentos pessoais de alguns professores, o que perpassa por seus sentidos pessoais do que é ou não desejável no contexto escolar. Cabe também considerar que esses jovens e seus pais não mais correspondem ao modelo de alunos e pais esperado/idealizado pela escola e pelos professores para o qual ela estaria preparada.

A forma como as informações são registradas indica elementos subjetivos mediando, por exemplo, o entendimento do que seja desrespeito ao professor, ou mesmo da periculosidade daquele aluno ao desrespeitar o professor.

Contraditoriamente, os professores parecem vivenciar situações nas quais se sentem reféns, sem apoio ou respaldo da instituição escolar e familiar. No confronto cotidiano, sofrem, estressam-se e adoecem, e ao mesmo tempo buscam mecanismos meramente defensivos de "proteção" a partir de significados estereotipados atribuídos aos acontecimentos em sala de aula, geralmente divorciados de um sentido autêntico.

Para Vigotski (2006), os sentidos são pessoais, mas podem e devem ser acessados por meio do significado, elemento partilhado que possibilita a compreensão entre os sujeitos; mas o significado, grosso modo, pode divorciar-se do sentido e assim se configurar de forma estereotipada, se não preconceituosa.

Desta forma, o significado de violência sofrida e de aluno violento é resultante de uma frágil elaboração, construída sem a devida reflexão, de modo que nem sempre a dimensão pessoal pode se efetivar. As relações sociais e culturais estabelecidas e partilhadas no cotidiano da escola tendem a não possibilitar momentos de suspensão em relação ao cotidiano alienado. Assim, os professores experienciam o sentimento de impotência, desvalorizados que são pelos alunos e por seus pais. Esses sentidos parecem ancorados em suas representações de violência, juventude, pobreza e contexto sociocultural, marcadamente vivenciadas no confronto entre o aluno esperado e o que efetivamente adentra as salas de aula.

Baquero, Lemes e Santos (2001) afirmam que os jovens,

Marcados por suas vivências, constroem maneiras peculiares de perceber o mundo em que vivem e o seu entorno. Conscientes ou não disso, expressam as interpretações de suas experiências em relação ao lugar que poderia ser o caminho para a fuga da marginalidade e promessa de outras possibilidades - a escola, revelando expectativas e decepções nas suas relações com elas

Assim como as autoras acima referidas afirmam na conclusão de sua pesquisa com jovens egressos de medidas socioeducativas, consideramos que os alunos jovens, em sua maioria pobres e moradores de bairros violentos, não se enquadram nos padrões de aluno esperados pela escola formal, o que resulta em um grande número de registros nos livros sem qualquer efeito pedagógico/educativo e na construção de um dossiê que registra a suposta história de criminalidade dos sujeitos antes mesmo de os atos violentos terem sido efetivamente praticados. Diante dessa profecia, parece não restar à escola outro caminho a não ser o de se defender - e de forma frágil, isto é, com a ilusão de assim se "proteger". 


\section{Referências}

Aquino, J. G. (2011). Da (contra)normatividade do cotidiano escolar: problematizando discursos sobre a indisciplina discente. Cad. Pesqui., 41(143), 456-484.

Baquero, R. V. A., Lemes, M. A., \& Santos, E. A. dos. (2001). Histórias de vida de jovens egressos de medidas socieducativas: entre a margem e a superação. Educação, 34(3), 341-350.

Bardin, L. (1998). Análise de conteúdo. Lisboa: Edições 70.

Barrere, A., \& Martuccelli, D. (2001). A escola entre a agonia moral e a renovação ética. Educ. Soc., 22(76), 258-277.

Coimbra, C. M. B. (2000). Doutrinas de segurança nacional: banalizando a violência. Psicol. estud., 5(2), 1-22.

Corti, A. P., Freitas, M. V. de, \& Sposito, M. P. (2001). O encontro das culturas juvenis com a escola. São Paulo: Ação Educativa Assessoria, Pesquisa e Informação.

Charlot, B. (Org.) (2001). Os jovens e o saber: perspectivas mundiais. Porto Alegre: Artes Médicas.

Charlot, B. (2002). A violência na escola: como os sociólogos franceses abordam essa questão. Revista Sociologias, 8(4), 432443.

Debarbieux, E. (2001). A violência na escola francesa: 30 anos de construção social do objeto. (1967-1997). Educação e Pesquisa, 27(1), 163-193.

Debarbieux, E. (2002). Violência nas escolas: divergências sobre palavras e um desafio político. Em E. Debarbieux \& C. Blaya (Orgs.), Violência nas Escolas e Políticas Públicas (pp. 59 a 92). Brasília: UNESCO.
Debarbieux, E. (2005) Les dix commandements contre la violence à l'école. Cahiers Pédagogiques, 10(436), 62-63.

Gatti, B. A. (2005). Grupo Focal na Pesquisa em Ciências Sociais e Humanas. São Paulo: Líber Livros.

Leontiev, A. N. (1978). O desenvolvimento do psiquismo. São Paulo: Ed. Moraes Ltda.

Minayo, M. C. S. (1998). O desafio do conhecimento: pesquisa qualitativa em saúde. São Paulo: Hucitec.

Moro, N. de O. (2002). O "LIVRO PRETO" nas escolas da região dos Campos Gerais. Anais da I Jornada do HISTEDBR. Recuperado: 29 mai 2011. Disponível: http://www.histedbr.fae.unicamp.br/acer histedbr/jornada/jornada1/recorte2.html

Ratto, A. L. S. (2007). Livros de ocorrência: (in)disciplina, normalização e subjetivação. São Paulo: Cortez.

Silva, J. O. da, \& Ristum, M. (2010). A violência escolar no contexto de privação de liberdade. Psicol. cienc. prof., 30(2), 232-247.

Sousa, C. A. D., Nascimento, K., \& Azevedo, I. A. S.(2006). Registros em livros de ocorrência das escolas públicas de cidades localizadas a leste de Minas Gerais: uma análise documental. Anais I Seminário internacional de Direitos Humanos, Violência e Pobreza, Rio de Janeiro.

Vigotski, L. S. (2001). A construção do pensamento e da linguagem. São Paulo: Martins Fontes.

Vigotski, L. S. (2006). Psicologia Infantil - Obras Escogidas IV (2a Ed.). Moscou: Editorial Pedagógica.

Zaluar, A. (2004). Integração perversa: pobreza e tráfico de drogas. Rio de Janeiro: FGV. 


\section{Sobre as autoras}

Débora Cristina Fonseca (deboracf@rc.unesp.br)

Psicóloga, Doutora em Psicologia Social - PUC/SP, Professora Assistente Doutora, Departamento de Educação e do Programa de Pós Graduação em Educação, Instituto de Biociências, Universidade Estadual Paulista “Julio de Mesquita Filho” (UNESP-Rio Claro).

Leila Maria Ferreira Salles (leila@rc.unesp.br)

Psicóloga, Doutora em Educação - PUC/SP, Professora-Livre Docente, Departamento de Educação e do Programa de Pós Graduação em Educação, Instituto de Biociências, Universidade Estadual Paulista “Julio de Mesquita Filho" (UNESP-Rio Claro).

Joyce Mary Adam de Paula e Silva (Joyce@rc.unesp.br)

Doutora em Educação - UNICAMP/SP, Professora-Livre-Docente, Departamento de Educação e do Programa de Pós Graduação em Educação, Instituto de Biociências, Universidade Estadual Paulista “Julio de Mesquita Filho" (UNESP-Rio Claro).

O artigo foi desenvolvido com base nos dados coletados em uma das etapas da pesquisa "Violência de jovens e violência escolar: estudo sob a ótica do imaginário escolar e da inserção social", financiada pela FAPESP em Programa Especial (Ensino Público). A pesquisa é desenvolvida no grupo de Pesquisa: "Jovens, violência e educação".

Trabalho submetido à avaliação do Encontro de Didáticas e Práticas de Ensino (Endipe/2012), de forma reduzida (12 páginas). 